\title{
Masters of Sport: Graduate School Pathways of Aspiring Intercollegiate Athletics Professionals
}

\section{Laura M. Bernhard Stanford University, Stanford, CA}

lauramb@stanford.edu

\section{Kristina Navarro University of Wisconsin- Whitewater, Whitewater, WI}

navarrok@uww.edu

\author{
Siduri J. Haslerig \\ University of Oklahoma, \\ Norman, OK
}

haslerig@ou.edu

\author{
Derek A. Houston \\ University of Illinois at Urbana- \\ Champaign, Urbana, IL \\ dahousto@illinois.edu
}

\begin{abstract}
Intercollegiate athletic departments are complex organizations in need of individuals with specialized training and experience - credentials that aspiring practitioners have increasingly sought through graduate education. Despite the growing prevalence of graduate credentials, little is known about the motivations or choice processes of those seeking an advanced degree. Focusing on individuals enrolled in intercollegiate athletics administration graduate programs, this study employed an online survey to explore students' motivation to: (a) pursue graduate school; and (b) choose their specific program. In addition, this study explored how these program choices aligned with their career aspirations. A mixed methods approach, framed by Social Cognitive Career Theory, found that students pursue graduate education as a form of credentialing and to gain skills; respondents cited the program's nesting in the education department as a main factor in their choice and were purposeful in pursuing graduate education as a way to advance their career. Findings shed light on a sub-population (aspiring athletics professionals) and decision-making process (graduate program choice) that are not well understood, pointing to implications for graduate programs and athletic departments alike.
\end{abstract}

Keywords: College choice, graduate students, graduate education, intercollegiate athletics, Social Cognitive Career Theory

Material published as part of this publication, either on-line or in print, is copyrighted by the Informing Science Institute and Preeminent Leadership and Research Solutions, LLC. Permission to make digital or paper copy of part or all of these works for personal or classroom use is granted without fee provided that the copies are not made or distributed for profit or commercial advantage AND that copies 1) bear this notice in full and 2) give the full citation on the first page. It is permissible to abstract these works so long as credit is given. To copy in all other cases or to republish or to post on a server or to redistribute to lists requires specific permission and payment of a fee. Contact Publisher@InformingScience.org to request redistribution permission.

\section{Introduction}

The increased commercialization of college sport has led to the development of athletic departments that are now large, highly visible, complex, multi-million dollar organizations (Croissant, 2001). With the growth of "Big-Time Sport" (Sperber, 2000), the need for a trained and specialized workforce has increased 
along with interest in the field. Today, intercollegiate athletics administration includes a diverse array of professionals working in areas such as marketing, compliance, fundraising, and academic support in addition to the more conventional roles of administrators and coaches (Weight \& Zullo, 2015). While the traditional career trajectory of athletics administrators often included practical experience (e.g., as a coach, former student-athlete, or intern) and networking to enter the field (Mullin, 1980; Won, Bravo, \& Lee, 2013), credentialing in the form of graduate education has gained considerable traction (Comeaux, Brown, \& Sieben, 2015; Navarro, Haslerig, Bernhard, Houston, \& Raphael, in press). Indeed, earning a graduate degree is a viable way of distinguishing one's self in a highly competitive job market such as intercollegiate athletics (Parks \& Zanger, 1990; Savickas, 2005). And many consider a graduate degree a necessary prerequisite to enter and advance in the field given college athletics' placement within institutions of higher education (Navarro et al., in press).

The decision to enroll in a graduate program, thereby postponing entrance into the professional field and the earning of income, is an important choice. It also appears to be an increasingly popular one as the $21^{\text {st }}$ century job market continues to place high value on this credential (Savickas et al., 2009). Despite graduate education's popularity, little is known about graduate students and their path to a post-baccalaureate degree, especially for those in applied or professional fields such as intercollegiate athletics administration (Lewis \& Quarterman, 2006). While the undergraduate choice process has been studied and theorized extensively (e.g., Freeman \& Thomas, 2002; Hossler \& Gallagher, 1987; McDonough, 1997), the graduate choice process has received little attention. In fact, the body of work on graduate student choice is limited, with much of it focusing on single field, single institution samples, and the majority dating from over 30 years ago (e.g., Malaney, 1987; Parkhouse, 1978; Remus \& Isa, 1983). To this end, the current study investigates: (a) participants' motivations for pursuing graduate school in general; (b) participants' reasons for choosing their specific program; and (c) how this program choice aligns with participants' career aspirations. Drawing on Social Cognitive Career Theory (Lent, Brown, \& Hackett, 1994), the study used a mixed methods survey to collect the perspectives of students in two different types of intercollegiate athletics administration programs: traditional and professional.

\section{Literature Review}

\section{College Sports: A Growing Field}

Intercollegiate athletics have grown increasingly commercialized (Bowen \& Levin, 2011) with a subset of institutions - namely those classified as members of the Division I (DI) Football Bowl Subdivision (FBS) - developing into an industry known as "Big-Time Sport" (Sperber, 2000). The largest and most elite of these departments now support upwards of 800 student-athletes with over 200 full-time staff, and budgets of $\$ 100$ million dollars or more (Equity in Athletics, 2014). As the core functions of athletic departments have expanded from coaching and administering athletic competitions to the oversight of all aspects of student-athletes' college experiences, as well as the day-to-day operations of multimillion dollar businesses, corresponding growth has occurred in the roles of professional staff. In fact, many athletic departments now employ staff in such specialized areas as video editing, marketing, development or fundraising, communications, recruiting, licensing, event management, ticketing and sales. This specialization has resulted in a need for specific professional training and foundational knowledge for all intercollegiate athletics practitioners, and particularly for those that work directly with student-athletes - a body of knowledge that has increasingly been sought through graduate education. 


\section{Emergence of Graduate Sport Programs}

The traditional route to a job in athletics has been through experiential learning; namely, by being a coach, athlete, and/or by completing an internship (Cuneen, 1992; Cunningham \& Sagas, 2004; Mullin, 1980). While athletics is a field that still greatly values experience, there has also been growing acknowledgment of the need to develop a formal body of knowledge for future practitioners. This formalization started in 1966 with the creation of the first sport management program at Ohio University (Stier, 1993). Since then, the field has seen astounding growth with the number of sport management programs in the U.S. growing from 20 in 1980 to over 200 in 2000 (Parkhouse \& Pitts, 2001).

Sport management programs have historically been housed in physical education departments offering a broad curriculum that seeks to train a range of sports professionals (Hardy, 1987). In response to the increasing complexity of sport at all levels, academic curricula from these programs have divided into sub-disciplines, such as kinesiology, recreation, and international sport (Ulrich \& Parkhouse, 1982). Sport management programs have also taken a business-minded approach to sports, recognizing the need for leaders with a financial or management background, leading some programs to be housed in their university's graduate school of business (Center, 2011; Comeaux et al., 2015). While this evolving focus may serve leaders or managers in a general sport sense (e.g., recreational, professional), or those interested in the business side of college sports (e.g., fundraising, ticketing, sales), it may not serve those who work directly with studentathletes and may need training that addresses the unique complexities of intercollegiate athletics.

Scholars have called for athletics administrators who work directly with student-athletes to have specialized training similar to their campus counterparts in student affairs (Broughton \& Neyer, 2001; Navarro, 2014) - a training that should focus on both the individual and organizational context. For example, practitioners who work in academic or career counseling roles must have a clear understanding of the development stages individuals traverse during their college years, as well as an understanding of the context in which those individuals operate (namely that of the U.S. higher education system). Further, as student-athletes are encouraged to integrate into the larger campus environment and overcome boundaries of athletics space and place (Bernhard \& Bell, 2015), athletics practitioners must also be educated with this integration in mind. Without purposeful attention to student development theory and the organizational structure of higher education, sport management programs may not serve those who need a more in-depth understanding of the student-athlete experience (Jones, Brooks, \& Mak, 2008), calling for a new type of academic program.

\section{A Focus on Intercollegiate Athletics Administration}

In response, a new graduate track emerged: programs housed in departments or graduate schools of education with a specific focus on intercollegiate athletics administration (Jones et al., 2008). This academic nesting of athletics within education is both symbolic and practical as it mirrors that of the physical spaces on campus and acknowledges the inherent relationship between athletic departments and institutions (Bernhard \& Bell, 2015). While this merging of sports and higher education may be of interest to many aspiring athletics practitioners, by integrating theory with practice and focusing on the experience of the student-athlete, these programs may be of particular interest to those seeking to work specifically at the college level or directly with studentathletes (e.g., academic services, student-athlete development (Navarro et al., in press)).

In further response to student and practitioner need, two different types of graduate program have emerged. The first, "Traditional," follows a conventional academic track with two years of coursework culminating in a master's thesis or research project; the second, "Executive," follows a more professional or executive-based graduate model where students are fully employed or 
immersed in an internship and complete their course requirements through online or distance learning, supplemented by periodical intensive seminars. As this differentiation creates additional depth within an increasingly popular field, choosing the right graduate program that aligns with one's career aspirations has become even more nuanced (Kallio, 1995).

\section{Graduate Program Choice}

College choice has long been theorized as a multi-step process, popularly conceptualized by Hossler and Gallagher (1987) as consisting of the three stages of predisposition, search, and choice. Predisposition is when students determine whether or not they will continue their education past the secondary level; search encompasses the identification of a student's postsecondary options; and choice is the actual act of deciding which institution to attend (Hossler \& Gallagher, 1987). Various factors have been identified as playing a key role in students' choice processes including college reputation, cost, location, the influence of others (e.g., parents, friends, and counselors), and social climate (Hossler, Braxton, \& Coopersmith, 1989; Sevier, 1993). Research on the choice processes of various sub-populations, including those who are first-generation, from lower socioeconomic backgrounds, rural areas, and different racial groups, has revealed that different factors matter (e.g., Apostal \& Bilden, 1991; McDonough, 1997; Freeman \& Thomas, 2002; Ramirez, 2013; Whang \& Bernhard, 2014). This work has added to our understanding of the undergraduate college choice process, yet there is a dearth of research on the choice process for graduate students and what factors influence their decision (Lewis \& Quarterman, 2006).

Many studies on graduate student choice have relied on single field or single institution samples (Poock \& Love, 2001), are largely descriptive (Kallio, 1995), purely quantitative (Dam, 2014), or outdated (e.g., Malaney, 1987; Parkhouse, 1978; Remus \& Isa, 1983). Similar to the undergraduate process, graduate choice is seen as a multi-step process, albeit one more strongly affected by the age of the student and his or her developmental stage (Kallio, 1995). The initial decision to pursue graduate work is commonly driven by a desire to learn more about a specialty, improve one's job prospects, or the need for a post-baccalaureate degree to advance in the field (Malaney, 1987). In terms of actual program choice, graduate students rely on many of the same factors as undergraduates including academic reputation of the institution, quantity and quality of interaction with faculty, and program size (Lewis \& Quarterman, 2006). A distinction for graduate students, however, is the greater influence of spouse, family, and work considerations rather than that of social climate or peers (Kallio, 1995). Further, graduate students place particular emphasis on location-less so in terms of the geography or urbanicity that may resonate with undergraduates, and more so in terms of residency status, convenience, and work opportunities for both them and their spouse (Kallio, 1995). Thus, professional aspirations do factor into individuals' decisions to continue their education, as well as their specific program choice-an important consideration for aspiring athletics professionals given the breadth of career paths within intercollegiate athletics departments and graduate programs.

\section{Theoretical Framework}

To frame this study, we drew upon Lent et al.'s (1994) Social Cognitive Career Theory (SCCT). The theory's foundation is Bandura's (1986) Social Cognitive Theory which focuses on human behavior; namely, an individual's decision-making processes. SCCT builds on this by specifically considering how an individual's career and academic interests mature, how his or her career choices develop, and how these choices are then turned into action. To this end, SCCT is comprised of three main tenets: self-efficacy, outcome expectations, and personal goals. These components influence each other in a reciprocal or "triadic" relationship, whereby individuals set personal goals based on activities for which they feel competent in and expect positive outcomes. The interplay of these three tenets, which depends heavily on one's environment and personal 
identity development, ultimately shape an individual's career interests and choices throughout their life (Lent et al., 1994).

While this theory has been applied to undergraduate sub-populations in higher education (e.g., Robbins, Lauver, Le, Davis, \& Langley, 2004), it is rarely utilized in studies on graduate students. And yet, graduate students seem better positioned to consider specific career options, gauge their self-efficacy, and have realistic outcome expectations. Thus, we applied SCCT to a subpopulation of graduate students; specifically, individuals who aspire to work in intercollegiate athletics. We considered how participants' life experiences, self-efficacy, and expectations influence their career aspirations and decision-making processes, particularly in choosing to attend graduate school and in selecting a specific graduate program. Through the lens of SCCT, we ultimately sought to better understand graduate student behavior and choice processes with respect to program choice and career preparation.

\section{Methods}

In looking at individuals currently enrolled in a Master's of Education program with a focus on intercollegiate athletics, the following research questions guided this study: (a) What are students' motivations to pursue a graduate degree?; (b) What led them to choose their specific program?; (c) How does this align with their career aspirations?; and (d) Are there differences by program type? To answer our research questions, an online survey instrument was developed based on a review of the literature, our theoretical framework, previously validated surveys, and the research team's experiences as both graduate students and members of intercollegiate athletics departments. Piloting the survey with a sample of the targeted population and scholars familiar with the field elicited feedback on the survey format, question structure, and overall content (Barak, Cherin, \& Berkman, 1998).

The survey instrument was comprised of multiple choice, Likert-scale, and open-ended questions. Of the non-demographic questions, the majority (63\%) of the survey consisted of open-ended items regarding participants' reasons for pursuing a graduate degree, their career aspirations, as well as their intercollegiate athletics and graduate program experiences. The analysis for this study primarily focused on four of the open-ended questions, with the item text and corresponding number of responses included in Table 1.

Table 1. Survey questions with number of respondents

\begin{tabular}{lc}
\hline Question text & $\mathrm{n}$ \\
\hline Describe your motivations for pursuing a graduate degree program. & 76 \\
$\begin{array}{l}\text { Your program focuses on intercollegiate athletics and is affiliated with a higher } \\
\text { education department. Did you consider this distinction when applying to and }\end{array}$ & 75 \\
eventually choosing your graduate program? & 64 \\
$\begin{array}{l}\text { Why did you choose your current graduate program over other sports-related } \\
\text { programs? }\end{array}$ & 60 \\
\hline
\end{tabular}

Open-ended items were chosen because they allow for a bridging "between the investigator's assumptions about the meanings of words and the meanings given to the same words by the respondent" (Schuman, 2008, p. 63), providing an interpretive depth to respondents' answers. Text boxes were included after every question prompt and, while some participants chose to answer in brief (e.g., single words or lists), the majority gave longer, sentence-like responses that helped elucidate their reasoning. The survey also collected various demographic measures including ra- 
cial/ethnic identification, undergraduate major and institution, and highest level of athletic participation.

\section{Data Collection and Sample}

Our sample consisted of students who were currently enrolled in or were recent graduates of a master's level education program with a focus or concentration on intercollegiate athletics administration. Given the small field of study, a total of four specific programs were targeted and the program director at each site was contacted via email. We employed purposeful sampling (Patton, 2002) in order to select sites with a high level of buy-in from the administration, an approach we anticipated would result in higher response rates. This article focuses on participants at two programs, chosen because they represent distinct models: Traditional and Executive. Each program is situated at a large, selective, public research university with a highly successful NCAA Division I athletic program (i.e., both programs have won multiple national championships (Learfield Sports, 2015)). The first site (Traditional) represents a more traditional program consisting of full-time, primarily in-person classroom learning over the course of two years. The second takes a more professional or fully-employed student approach (Executive), consisting of an intensive summer session followed by distance learning courses with periodic on-site sessions, all completed within one calendar year. These dual models of education allow for a comparative study, adding nuance to our understanding of graduate school choice.

Once the programs were identified and permission from the administration secured, a campusspecific link to the Qualtrics survey was sent to each Program Director. Each graduate program then contacted all enrolled students and recent graduates (within the previous two years) via email inviting them to participate, while stressing that participation was voluntary. Three reminder emails, spaced one week apart, were sent to the program administrators for distribution to their students and the survey was closed after five weeks.

A total of 92 students initiated surveys. As all survey questions were optional, some participants skipped certain questions while providing relevant and insightful answers to others, meaning the response rate varied by question. The decision was made to limit the sample to participants who responded to at least one of the four main open-ended questions, resulting in a total of 76 respondents. The sample is 50\% female and 50\% male (across the full sample and within each program). For race/ethnicity, the overall sample is $70 \%$ white, $15 \%$ Black, and $9 \%$ identified as multiracial. Race/ethnicity breakdown by program is included in Table 2.

Table 2. Self-identified race/ethnicity by program

\begin{tabular}{lrrrr}
\hline & \multicolumn{2}{c}{ Traditional } & \multicolumn{2}{c}{ Executive } \\
\cline { 2 - 5 } & $\mathrm{n}$ & \multicolumn{1}{c}{$\%$} & $\mathrm{n}$ & $\%$ \\
\hline American Indian or Alaskan Native & 1 & $3.6 \%$ & 1 & $2.1 \%$ \\
Asian or Pacific Islander & 0 & $0.0 \%$ & 1 & $2.1 \%$ \\
Black & 8 & $28.6 \%$ & 3 & $6.3 \%$ \\
Latino & 0 & $0.0 \%$ & 0 & $0.0 \%$ \\
Multi-racial & 5 & $17.9 \%$ & 2 & $4.2 \%$ \\
White & 13 & $46.4 \%$ & 40 & $83.3 \%$ \\
No response & 1 & $3.6 \%$ & 1 & $2.1 \%$ \\
\hline Total & 28 & $100 \%$ & 48 & $100 \%$ \\
\hline
\end{tabular}


Our participants ranged in age from 22 to 48 years across the full sample, with an average age of 26 for the Traditional group and 29 for the Executive group. Over half of all respondents $(n=41$, $54 \%$ ) participated in college athletics under the jurisdiction of the NCAA or NAIA (see Table 3).

Table 3. Highest level of athletic participation by program

\begin{tabular}{lrrrr}
\hline & \multicolumn{2}{c}{ Traditional } & \multicolumn{2}{c}{ Executive } \\
\cline { 2 - 5 } & $\mathrm{n}$ & \multicolumn{1}{c}{$\%$} & $\mathrm{n}$ & \multicolumn{1}{c}{$\%$} \\
\hline Professional & 1 & $3.6 \%$ & 1 & $2.1 \%$ \\
NCAA/NAIA & 14 & $50.0 \%$ & 27 & $56.3 \%$ \\
College Club or Recreational & 2 & $7.1 \%$ & 3 & $6.3 \%$ \\
High School Varsity & 6 & $21.4 \%$ & 9 & $18.8 \%$ \\
Other & 0 & $0.0 \%$ & 2 & $4.2 \%$ \\
No response & 5 & $17.9 \%$ & 6 & $12.5 \%$ \\
\hline Total & 28 & $100 \%$ & 48 & $100 \%$ \\
\hline
\end{tabular}

\section{Data Analysis}

Due to the exploratory nature of the work, responses to each question were coded using an open and axial coding schematic (Creswell, 2013). All data were downloaded from Qualtrics and put into Microsoft Excel, grouped by institution. The research group read the open-ended responses independently and identified initial themes, then met to determine preliminary codes. Following the initial coding processes, analytic memoing and pattern coding data analysis techniques were utilized to condense the number of axial codes and further evaluate the data (Bogdan \& Biklen, 2007). Themes were then explored by program type and participant demographics to identify differences or trends.

Given the qualitative nature of the analysis, the positionality of the researchers must be acknowledged. The research team is both multi-racial and mixed gender, and three have been involved in NCAA intercollegiate athletics as student-athletes or working professionals. Two of the researchers attended a master's program with a curriculum centered on intercollegiate athletics while two are current faculty members in higher education graduate programs with a focus on intercollegiate athletics. These experiences certainly incited our interest in the topic, while the diversity of backgrounds helped shape our interpretation of the data and generate our implications for research and practice.

\section{Findings}

The research questions focused on students': (a) motivation to pursue graduate work; (b) graduate program choice; and (c) career alignment. Our analysis of the data shows that graduate students were purposeful both in their exploration and selection of a graduate program, and these processes were often linked to their career goals. The main themes across both institutions are identified and discussed below, and any differences by program type are highlighted.

\section{Pursuing Graduate Education}

When participants were asked about their motivation or reasoning for pursuing graduate work in this sub-field, two distinct lines of reasoning emerged: obtaining a graduate degree as a form of credentialing or requisite step for entry into the field versus those who sought to develop their knowledge and skills, with the specific goal of supporting student-athletes. The first theme, of 
career preparation, was expressed by a total of 40 participants (53\%; all percentages are based on the number of responses for each question) who saw an advanced degree as a prerequisite qualification to entering the field. For one respondent from the Executive program, deciding to attend graduate school was an obvious choice, reasoning that a graduate degree in this specialization was simply "preparation for a job in intercollegiate athletics." While another from the Traditional program wrote they felt "pressure" to have a master's degree, citing "external factors such as job descriptions" as being a main reason for their enrollment. A total of 5 participants (7\%) cited a graduate degree as necessary for advancing in the field, and another $5(7 \%)$ felt it gave them a "competitive edge" in the job market. As one participant said, "I believe a master's degree will help give me a competitive advantage to get hired in this industry."

On the other hand, a number of respondents $(\mathrm{n}=10,13 \%)$ wrote of a desire to gain knowledge and skills, and to enhance their understanding of the field of intercollegiate athletics. One participant from the Executive program noted, "I wanted to complement my work experience in intercollegiate athletics with the theory," while another cited a desire for an "educational foundation." Another distinct theme was that of supporting student-athletes. Almost one quarter of all respondents $(\mathrm{n}=18,24 \%)$ expressed a specific desire to work directly with student-athletes and were seeking academic knowledge to supplement their mission. As one participant from the Traditional program wrote, "I wish to learn more about the world of intercollegiate athletic administration and be more of a service to student-athletes." Another participant from the Executive program shared, "I'm passionate about helping student-athletes achieve high levels of success not only in their sport but also in the classroom." Even though these individuals were driven by academic interests, they were also aware of the benefits of a graduate degree for gaining entry into the field. As one Executive program participant strategically noted, attending graduate school was a way to both "increase [my] education and set myself up for better opportunities in entry into the job market."

Given the variation in program models (e.g., Traditional and Executive), participants' reasons for attending graduate school were examined by program model. When combining the career-based themes (graduate degree as career preparation, gaining a competitive edge, and advancing in the field), a total of $75 \%$ of participants from the Traditional program cited these reasons, compared to $60 \%$ of Executive participants. Approximately one quarter of respondents from each program ( $21 \%$ for Traditional and $25 \%$ for Executive) stated they were driven to continue their education with the specific career goal of working with student-athletes. Either way, it was clear that these aspiring athletics professionals saw graduate school as a beneficial, even necessary, step to joining the field. Furthermore, even as some pursued the degree for enhancement of knowledge or skills, almost all acknowledged the practical benefits gained by earning a graduate degree in a competitive professional field (Savickas, 2005).

\section{Graduate Program Choice}

Given the specific focus of the programs we studied-higher education master's with a concentration in intercollegiate athletics administration-we were very interested in our participants' reasoning for selecting their specific program. Did participants consider the program being housed in the education department to be important? What about the specific focus on intercollegiate athletics? In short, the answer to both questions is yes. The vast majority of participants across both programs ( $\mathrm{n}=62,82 \%)$ wrote that the programs' distinction (being housed in Education and focusing on intercollegiate sports) was a major factor in deciding which program to apply for and ultimately attend. For these participants, this distinction was a clear benefit as many wrote of a desire for a deeper understanding of intercollegiate athletics and the role academics plays in the student-athlete experience. One participant from the Executive program wrote, "I specifically chose this program because it emphasized sports in an educational setting," while another reflect- 
ed, "I felt as though having an understanding of how the athletic department fit within the university structure and system was a very important aspect of being able to serve student-athletes in the best way possible." A higher percentage of respondents from the Executive program (88\%) than the Traditional program (75\%) cited the program's housing in the Education department as a deciding factor in their choice. Interestingly, eight of our participants earned their Bachelor's in sports management, perhaps making them uniquely qualified to speak to the value of their graduate program's specific focus. Indeed, seven of them (88\%) said they considered the distinction of their master's program, and saw differentiation from the more general sports management program as a positive. As one participant from the Traditional program shared, "I have a BA in sport management and I wanted to learn about athletics as it relates to college specifically."

In addition to the programs' niche focus, other reasons cited by participants for choosing their program included location, program prestige, opportunities for graduate assistantships, and for those in the Executive program-the unique features of that model (see Table 4).

Table 4. Reasons for choosing specific graduate program by program type $(n=56)$

\begin{tabular}{lrrrr}
\hline & \multicolumn{2}{c}{ Traditional $(\mathrm{n}=19)$} & \multicolumn{2}{c}{ Executive $(\mathrm{n}=37)$} \\
\cline { 2 - 5 } & $\mathrm{n}$ & $\%$ & $\mathrm{n}$ & $\%$ \\
\hline Location & 10 & $52.6 \%$ & 17 & $45.9 \%$ \\
Prestige of Athletics Department & 4 & $21.1 \%$ & 2 & $5.4 \%$ \\
Prestige of University & 1 & $5.3 \%$ & 6 & $16.2 \%$ \\
Graduate Assistantship & 3 & $15.8 \%$ & 9 & $24.3 \%$ \\
Unique Program Features & --- & --- & 20 & $54.1 \%$ \\
\hline
\end{tabular}

Note: Some responses covered more than one theme and were coded into multiple categories. Therefore, the total number of responses does not add up to the total number of respondent.

Location, in fact, was the second most commonly cited reason by participants $(n=27,48 \%)$ for their program choice. While some referred to the appeal of the host city or geographic region of the country (and one even cited the athletic conference as influential), the majority wrote about location in terms of proximity to family or convenience, as they were already settled in a community and wanted to remain there. Given the more flexible and short-term nature of the Executive program, it is not surprising that the proximity-to-family rationale seemed to resonate more strongly with those from the Traditional program ( $n=6,21 \%$ vs. $n=1,2 \%$ for Executive). For some students, location (including the consideration of in-state tuition) was the main reason they cited for choosing their graduate program - sometimes over and above the program's specific focus or structure. This finding highlights a key feature in graduate students' decision-making processes, differentiating them from their undergraduate counterparts, and pointing to the importance of life stage development (Kallio, 1995).

Another notable reason for participants choosing their specific program was prestige. While some $(n=7,13 \%)$ referenced the prestige of the academic department or institution, others, in fact, noted the prestige and success of the athletic department itself. A number of participants across both programs $(n=6,11 \%)$ noted they were attracted by "the quality and success of the athletic program" or, as one participant from the Traditional program reported, their institution "is home to some of the best athletics teams and some of the best support staff available, [and] I wanted to learn from the best." Indeed, athletic prestige seemed particularly important to some participants, and something that graduate programs can draw on for recruiting purposes, particularly if they have a strong relationship with their athletic department and can offer internship or work opportunities to students. 
Connections to the athletics department tied in directly to the last commonly cited reason $(\mathrm{n}=12$, $21 \%$ ), as survey participants from both programs noted the appeal of graduate assistantship or internship opportunities when selecting their graduate program. How this manifested differed by program; for the Traditional program, many students had the opportunity to work in that institution's athletic department - an opportunity that would not only provide them with experience and professional connections, but that may also help fund their education. As one respondent from the Traditional program said, he was particularly attracted by "the ability to work closely with the whole athletic department through the graduate assistant positions." Alternatively, the Executive program allowed students to hold internships at other institutions or sport organizations, a freedom which was very appealing for some. And for three participants, the procurement of an assistantship was the sole reason for choosing their program. In the end, the opportunity to gain experience and network while attending graduate school held strong value for a number of participants, especially as intercollegiate athletics remains a field that heavily values work experience and often relies on personal connections for hiring (Won et al., 2013).

Finally, as our sample drew from two very different graduate program models we presumed that program structure, length, and design would factor into many students' choice of program. As the majority of master's programs feature two years of classroom learning, students in the Executive program cited the program's length (one full calendar year), format (summer intensive with extended weekend seminars throughout the year), and focus on professional development (e.g. freedom to have an internship or position outside the institution and numerous networking opportunities) as reasons for selecting the program. Indeed, a majority of students from the Executive program ( $n=20,54 \%)$ cited the format and length of their program as not only unique but also a key factor in their decision. In contrast, students in the Traditional program more often cited the program's focus on intercollegiate athletics and nesting within the Education department, rather than the format, as factors in their choice.

\section{Career Alignment}

A total of 60 students shared their long-term career aspirations. Of these, 47 (78\%) expressed interest in pursuing a job in intercollegiate athletics. Despite the distinct difference in program type (Traditional and Executive), the breakdown in career field and specific types of careers cited by participants was very similar across the two programs (see Table 5).

Table 5. Career aspirations by program $(n=60)$

\begin{tabular}{lrrrr}
\hline & \multicolumn{2}{c}{ Traditional $(\mathrm{n}=23)$} & \multicolumn{2}{c}{ Executive $(\mathrm{n}=37)$} \\
\cline { 2 - 5 } & $\mathrm{n}$ & \multicolumn{1}{c}{$\%$} & $\mathrm{n}$ & \multicolumn{1}{c}{$\%$} \\
\hline Intercollegiate Athletics & 19 & $82.6 \%$ & 28 & $75.7 \%$ \\
Non-College Sports & 1 & $4.3 \%$ & 8 & $21.6 \%$ \\
Terminal Degree $^{\mathrm{a}}$ & 5 & $21.7 \%$ & 1 & $2.7 \%$ \\
\hline
\end{tabular}

${ }^{a}$ This code overlapped with others in the Traditional group, so the total number of themes does not add up to the total number of respondents.

A total of 9 participants (15\%; 8 Executive and 1 from Traditional) had professional interests outside of intercollegiate athletics, including professional sports, non-profits, high school athletics, and recreation. A few participants $(n=6,10 \%)$ also expressed interest in or were already pursuing a terminal or doctorate degree in the field, including five from Traditional and one from the Executive program.

As stated earlier, many of our participants saw a graduate degree as a beneficial, or even necessary, step to establishing a career in intercollegiate athletics. Participants recognized that the field 
has become increasingly competitive and saw a graduate degree as a way to differentiate themselves. One student in the Traditional program, interested in public relations or communications, wrote that his motivation for graduate school was "to get ahead. There are not many jobs in intercollegiate athletics administration, so every little bit counts." An Executive program participant who had worked in Sports Information as an undergraduate, reflected on this experience in describing his motivations: "I really loved everything about working for an athletic department and I knew to make it farther in this industry that I needed at least a master's degree to separate myself." Thus, participants' career aspirations impacted their decision to pursue a graduate degree, in either program format, in order to access or progress in a highly competitive field. And, different from undergraduates, these individuals have a clear sense of where they want to be and are using their graduate program as a strategic move to achieve goals and advance in their career path (Savickas, 2005).

When asked about their motivation to pursue a graduate degree with a focus on intercollegiate athletics, almost a quarter of participants $(n=18,24 \%)$ expressed a specific interest in better supporting or serving student-athletes. Of these, $13(72 \%)$ were former NCAA or NAIA college student-athletes who reflected, both negatively and positively, on their own experiences as a motivation to enter the field. Some participants had worked with athletes at the high school or college level and wrote of their subsequent frustration with "the system" or with how they perceived athletes were being treated. As one participant in the Traditional program explained, "as a high school teacher I was seeing the separation between what student-athletes were being told and prepared for to what they actually needed to be told and prepared for at the collegiate level in regards to compliance rules and academic readiness." Alternatively, one participant in the Executive program wrote how he had a "phenomenal experience as a student-athlete, [and wanted] to "pay it forward' and provide opportunities for future student-athletes to have as great of an experience as I had." Another participant from the Traditional program reflected on the important role athletics support staff can play in shaping student-athletes' experiences, stating, "I aspired to pursue a career intercollegiate athletics because I wanted to be an advocate and supporter of student-athletes of color." Despite the variation in personal experiences, these individuals were all driven to earn their master's degree in order to better support student-athletes and create a positive college experience. And when reflecting on their reasons for pursuing the degree and choosing their specific program, these participants all cited personal life experiences and successes in the field as paramount to their goal-setting and decision-making, a finding consistent with SCCT (Lent et al., 1994).

\section{Discussion}

This study focused on a unique sub-population of students; namely, graduate students interested in pursuing a career in intercollegiate athletics. Findings explored what drove participants to pursue a graduate degree, how these individuals chose their specific program, and how this pathway aligned with their career aspirations. Results from this study support the notion that graduate students are, by nature, a more focused subset of students in higher education who begin their educational program with a career-based goal in mind (Malaney, 1987). Indeed, the majority of our respondents noted the value placed on a master's degree within the field of intercollegiate athletics and cited this as a factor in their decision to pursue a graduate degree. Many viewed a master's degree as a form of credentialing for entry into the field or, for those already established in the field, as a way to move up or into a different area of intercollegiate athletics. The notion of credentialing as a way of gaining entry into or promotion within a field aligns with previous research on graduate students' motivations for pursuing graduate school (Malaney, 1987), and fits the SCCT framework (Lent et al., 1994). 
Participants' reasons for pursuing graduate education were very similar across the two program types. The only notable difference was that a smaller percentage of students from the Executive program cited career considerations (e.g., to enter into or advance in the field) as a driving factor in their decision to attend graduate school. As these students are all fully employed or engaged in a full-time internship, their hands-on or experiential learning experiences and networking opportunities may seem more central to their career preparation than the formal master's curriculum.

\section{The Higher Education Context}

The other main reason for pursuing a graduate degree, as cited by our participants, was to gain knowledge and an educational foundation of the field. And when asked what led them to choose their specific program, a number of participants mentioned a clear desire to develop an understanding of higher education systems as well as the intercollegiate athletics enterprise. This suggests that aspiring athletics professionals recognize intercollegiate athletic departments are part of the larger institutions and must function within the higher education model, a relationship that clearly differentiates college sports from its professional counterparts.

As traditional sport management programs tend to focus on the business side of sport, curricula often lack background on the role of athletics within higher education and the higher education system as a whole (Comeaux et al., 2015). This knowledge may be of particular interest to those aiming for support services or compliance positions; however, given recent criticisms and legal proceedings regarding the current collegiate model (see O'Bannon v. NCAA, 2014; Sperber, 2000), it seems that all aspiring intercollegiate athletics professionals would benefit from a foundation in higher education. Indeed, many of our participants, regardless of their intended career, acknowledged the value of a curriculum rooted in higher education and stated they intentionally chose their program in recognition of the changing landscape of intercollegiate athletics administration. Thus, consistent with SCCT, it seems that both individual motivations and external influences shaped the graduate programs selected by individuals in our sample (Lent et al., 1994).

\section{External Influences on Program Choice}

In terms of motivations for choosing a specific graduate program, environmental and familial commitments also played a large factor. While many participants cited the institution's location as a factor, fitting with previous research on college choice (Hossler et al., 1989), it was how they referred to location that was notable. In research on undergraduates, location is most commonly cited in terms of urbanicity or desirability of the locale (Noel-Levitz, 2012). Our participants more often cited location in terms of proximity to family or convenience as they were already settled in a community and wanted to pursue a graduate degree that fit with their current life situation. This finding points to the influence of family and spouses, highlighting how the graduate choice process may differ from that of undergraduate students (Kallio, 1995).

Another way that location influenced graduate students was in terms of networks. A few of our participants were keenly aware that development of strong personal and professional networks will be crucial to their advancement in a dynamic and competitive career field such as intercollegiate athletics. For example, many of our respondents noted that they valued the connections within their graduate cohort and with professors who could assist with job placement or promotion. These individuals were strategic in committing to a geographic location for school as they wanted to create connections where they ultimately wanted to establish their career. This finding directly supports SCCT as individuals are making career-related decisions based on expectation of desired outcomes and personal goals (Lent et al., 1994). 


\section{Valuing Student Development}

In addition to those who perceived the value of a master's degree in higher education as a way to better understand the context in which college sports operates, others noted the utility of the focus on students. In fact, a clear sub-theme developed among participants with career aspirations to support and serve student-athletes. Their desire to work from a student development standpoint depicts a different sense of perceived value for a master's degree housed in education and focused specifically on intercollegiate athletics. For these graduate students, there was greater value in a curriculum that integrated educational and student development theories rather than general sport and business administration. This is indicative of the evolution of intercollegiate athletics as a field and subsequent shift in the type of training valued for aspiring athletic leaders (Cuneen, 1992). Namely, aspiring athletics professionals who seek to work directly with student-athletes appear to recognize the need to be trained not only from an administrative and organizational leadership framework, but also desire programs that provide training on student development. This finding suggests that while credentialing is indeed important (i.e., a master's degree continues to be seen as a requirement for professional advancement in college athletics), graduate education can also be reflective of a changing landscape.

\section{Applying SCCT to Graduate Program Choice}

As outlined previously, SCCT focuses on three main tenets including self-efficacy, outcome expectations, and personal goals (Lent et al., 1994). To better understand these concepts we focused on how SCCT applies to graduate students in the field of athletic administration as they craft career plans and choose graduate programs. In terms of self-efficacy, individuals shared a need to understand higher education systems to succeed both personally and professionally. Graduate students also utilized outcome expectations about the job market to inform their decisions of both pursuing a graduate degree and selecting a program. Finally, while personal goals appear solidified (to enter the field), developing a network and advancing in the profession were clearly considered as students made decisions about their graduate program choice.

\section{Implications}

As more individuals intend to pursue graduate school, graduate program directors and faculty alike desire a better understanding of graduate students' motivations and processes for choosing a program (Jones et al., 2008). Research on the aspirations and decision patterns of aspiring graduate students can assist with program development and student recruitment efforts. Such information can assist program directors as they seek to enhance curricula to target the specific educational and training needs of this unique population (Kallio, 1995).

\section{Implications for Graduate Program Practitioners}

Moving forward, program faculty should attend to the specificity of intercollegiate athletics as a unique context and work to diversify curriculum to include a focus on higher education and student development. Findings suggest graduate students were particularly drawn to the focus on the college context, understanding the higher education system, and specific experiences of studentathletes. In addition, program directors must consider the multifaceted roles the contemporary athletic administrator plays across NCAA divisions, NAIA schools, and even community colleges. Given that the majority of athletic administration positions are outside of Division I, at institutions where administrators often have more interaction with campus and student populations, graduate programs may consider a shift to provide a more holistic curriculum that includes the larger context of higher education leadership (Navarro, 2014). 
Next, as many participants were former student-athletes, faculty should draw on these experiences, both positive and negative, to relate classroom learning to real-life situations. Graduate students also bring a wide range of previous experiences working in athletic departments as undergraduates, post-collegiately, and/or currently. It is important to understand students' prior (and present) connections to the field, as well as their motivations for pursuing a career in intercollegiate athletics. Program faculty and staff should work to relate the curriculum to students' interests, viewing graduate students as informed consumers. Further, as social justice issues (e.g., student-athletes' rights (O'Bannon v. NCAA, 2014)) are increasingly punctuating the conversation, and as some of our participants view themselves as advocates for student-athletes, faculty should incorporate readings and discussions that address the changing landscape of intercollegiate athletics.

Finally, location and the availability of graduate assistantships or internships within athletics were major decision-making factors for graduate students. Traditional program participants were more likely to cite proximity to family and convenience as they were already being settled in the area as main reasons for choosing their program. Thus, for traditionally structured programs, recruiting locally may be key (perhaps even from their own undergraduate population), while programs that target working professionals can reach more regionally. Given the import of assistantships, faculty and program administrators should work to build positive relationships with their athletic departments to assist students with placement, career transition, and merging of theory with practice. As students gain invaluable work experience, athletics departments are also able to take on a developmental role in shaping future leaders as well as the profession. This would not only create a mutually beneficial experience for departments and students alike, but could result in positive learning outcomes, more directed career aspirations, and a strong sense of self-efficacy for both current and future athletics leaders.

\section{Opportunities for Future Research}

There are several limitations to this study that affect the generalizability of the findings and point to areas for future research. First, survey work, particularly online questionnaires, raises questions of participant reliability (Creswell, 2013). Our analysis necessarily assumes that responses from each participant are valid and represent the experiences in question. Surveys also do not allow for researcher follow-up or member-checking for understanding and interpretation, and are thus limited in their ability to address participants' full reasoning process. We sought to address this limitation by designing our survey to consist largely of open-ended questions intended to elicit richer responses, but interviews and focus groups would allow for a deeper understanding of students' choice processes.

Additionally, our sample draws from two specific graduate programs and may not be representative of all graduate students in this sub-field or even of the graduate population at either institution. Given the specificity of each program's focus and structure, it may be difficult to generalize findings beyond similar program and institutional contexts. The issue of selection bias may also be a factor, as students had already selected a program that focuses on intercollegiate athletics over other graduate sports programs. Further, some respondents did not complete all surveys items, allowing for the possibility of item non-response bias. As the full population of students enrolled in master's programs with a focus on intercollegiate athletics is not known, it is not possible to determine if our sample is representative of this group or if there are any differences between respondents and non-respondents.

Researchers should continue to explore comparisons between students who have completed graduate-level sport management and intercollegiate athletics programs to better understand this niche focus. Work exploring the pathways of those who completed an undergraduate degree in sports management and Master's in Education with a focus on intercollegiate athletics would add addi- 
tional nuance. Studying students' preparation patterns and placement rates in the field can point to what knowledge and experience employers value when hiring. These studies could be framed from a workforce development lens to understand desired outcomes which could then be used to shape curriculum and programming. And as students are trying to meet the perceived needs of departments, it would also be informative to speak to athletic directors or those in charge of hiring in their respective areas to better understand what knowledge, skill sets, and training are most desirable for current positions, and to further triangulate the data.

Graduate program decisions are typically rooted in discussions of resources, often in the form of time and money, both of which are usually limited. Accordingly, additional work in the area of general graduate school choice is needed to elucidate the choice processes of graduate students and how these differ from their undergraduate peers. Collectively, qualitative, quantitative, and mixed methods studies can help drive future curricular plans and recruiting strategies at the campus level.

\section{Conclusion}

The field of intercollegiate athletics administration, as well as interest in the profession, continues to grow (Jones et al., 2008). Given the increasingly competitive field, many aspiring intercollegiate athletics practitioners see graduate degrees as a way of differentiating themselves from the competition (Savickas, 2005). In response to this, and the view of graduate education as a form of credentialing, the number of graduate-level programs focusing on sports, and intercollegiate athletics specifically, has increased nationwide (Comeaux et al., 2015; Weese, 2002). As there are now more, and more varied, graduate program choices available, aspiring practitioners need to make informed decisions about whether to pursue higher education, as well as in what format. In addition, a greater understanding of students' decision-making process may help faculty and ad-

ministrators better prepare their students as well as refine recruitment of future cohorts. By studying the motivations and choice patterns of graduate students in the applied field of intercollegiate athletics, this study adds to our understanding of this niche field, and more broadly, speaks to the choice process of graduate students - an understudied yet important population of students.

\section{References}

Apostal, R., \& Bilden, J. (1991). Educational and occupational aspirations of rural high school students. Journal of Career Development, 18(2), 153-160.

Bandura, A. (1986). Social foundations of thought and action: A social cognitive theory. Englewood Cliffs, NC: Prentice-Hall.

Barak, M. E. M., Cherin, D. A., \& Berkman, S. (1998). Organizational and personal dimensions in diversity climate ethnic and gender differences in employee perceptions. The Journal of Applied Behavioral Science, 34(1), 82-104.

Bernhard, L. M., \& Bell, L. (2015). Best practices in academic support services for student-athletes: Considerations for location. In E. Comeaux (Ed.), Data-informed practices in academic support centers for college athletes (pp. 125-142). Charlotte, NC: Information Age Publishing.

Bogdan, R. C., \& Biklen, S. K. (2007). Qualitative research for education (5th ed.). Boston, MA: Pearson Education.

Bowen, W. G., \& Levin, S. A. (2011). Reclaiming the game: College sports and educational values. Princeton, NJ: Princeton University Press.

Broughton, E., \& Neyer, M. (2001). Advising and counseling student athletes. New Directions for Student Services, 2001(93), 47-53. 
Center, K. R. (2011). Characteristics and professional qualifications of NCAA Divisions II and III athletic directors. Master's thesis, University of Tennessee, Knoxville.

Comeaux, E., Brown, A., \& Sieben, N. P. (2015). Issues in athletic administration: A content analysis of syllabi from intercollegiate athletics graduate courses. Innovative Higher Education, 40(4), 359-372.

Creswell, J. W. (2013). Research design: Qualitative, quantitative, and mixed methods approaches. Thousand Oaks, CA: Sage.

Croissant, J. L. (2001). Can this campus be bought? Commercial influence in unfamiliar places. Academe, 87(5), 44-48.

Cuneen, J. (1992). Graduate-level professional preparation for athletic directors. Journal of Sport Management, 6(1), 15-26.

Cunningham, G. B., \& Sagas, M. (2004). Group diversity, occupational commitment, and occupational turnover intentions among NCAA Division IA football coaching staffs. Journal of Sport Management, 18, 236-254.

Dam, S. A. (2014). What matters most? Factors influencing choice of a student affairs master's program. Master's thesis, University of Nebraska, Lincoln.

Equity in Athletics. (2014). Data analysis cutting tool. Retrieved from http://ope.edu.gov/athletics/

Freeman, K., \& Thomas, G. E. (2002). Black colleges and college choice: Characteristics of students who choose HBCUs. The Review of Higher Education, 25(3), 349-358.

Hardy, S. (1987). Graduate curriculums in sport management: The need for a business orientation. Quest, $39(2), 207-216$.

Hossler, D., \& Gallagher, K. S. (1987). Studying student college choice: A three-phase model and the implications for policymakers. College and University, 62(3), 207-221.

Hossler, D., Braxton, J., \& Coopersmith, G. (1989). Understanding student college choice. Higher Education: Handbook of Theory and Research, 5, 231-288.

Jones, D.F., Brooks, D. D., \& Mak, J. Y. (2008). Examining sport management programs in the United States. Sport Management Review, 11(1), 77-91.

Kallio, R. E. (1995). Factors influencing the college choice decisions of graduate students. Research in Higher Education, 36(1), 109-124.

Learfield Sports. (2015). 2014-15 Learfield Sports Director's Cup Division I Final Standings. Retrieved from http://grfx.cstv.com/photos/schools/nacda/sports/directorscup/auto_pdf/201415/misc_non event/1415DIIJJune4.pdf

Lent, R. W., Brown, S. D., \& Hackett, G. (1994). Toward a unifying social cognitive theory of career and academic interest, choice, and performance. Journal of Vocational Behavior, 45(1), 79-122.

Lewis, B. A., \& Quarterman, J. (2006). Why students return for a master's degree in sport management. College Student Journal, 40 (4), 717-728.

Malaney, G. D. (1987). Why students pursue graduate education, how they find out about a program, and why they apply to a specific school. College and University, 62(3), 247-258.

McDonough, P. (1997). Choosing colleges: How social class and schools structure opportunity. Albany, NY: SUNY Press.

Mullin, B. (1980). Sport management: The nature and utility of the concept. Journal of Sport and Social Issues: Arena Review, 4(3), 1-10.

Navarro, K. M. (2014). A conceptual model of Division I student-athletes' career construction processes. College Student Affairs Journal, 32(1), 45-60.

Navarro, K. M., Haslerig, S. J., Bernhard, L. M., Houston, D., \& Raphael, V.C. (in press). Athletic administration and higher education graduate programs: Innovative strategies and campus partnerships to 
prepare the next generation of intercollegiate athletic administrators. Journal for the Study of Sports and Athletes in Education.

Noel-Levitz. (2012). Why did they enroll? The factors influencing college choice. Coralville, IA: NoelLevitz, Inc. Retrieved from www.noellevitz.com/Factors2012

O’Bannon v. National Collegiate Athletic Association. (2014). 7 F. Supp. 3d 955, (N.D. Cal. 2014).

Parkhouse, B. L. (1978). Professional preparation in athletic administration and sport management: Graduate programs in the United States. Journal of Physical Education and Recreation, 49(5), 22-27.

Parkhouse, B. L., \& Pitts, B. G. (2001). Definition, evolution, and curriculum. In B. L. Parkhouse (Ed.), The management of sport: Its foundation and application (pp. 2-14). New York: McGraw-Hill.

Parks, J. B., \& Zanger, B. R. (1990). Sport \& fitness management: Career strategies and professional content. Champaign, IL: Human Kinetics Books.

Patton, M. Q. (2002). Qualitative evaluation and research methods (3rd ed.). Newbury Park, CA: Sage Publications.

Poock, M. C., \& Love, P. G. (2001). Factors influencing the program choice of doctoral students in higher education administration. Journal of Student Affairs Research and Practice, 38(2), 183-203.

Ramirez, E. (2013). Examining Lations/as' graduate school choice process: An intersectionality perspective. Journal of Hispanic Higher Education, 12(1), 23-36.

Remus, W., \& Isa, D. (1983). Predicting actual university enrollments. College Student Journal, 17(2), $137-140$.

Robbins, S. B., Lauver, K., Le, H., Davis, D., \& Langley, R. (2004). Do psychosocial and study skill factors predict college outcomes? A meta-analysis. Psychological Bulletin, 130(2), 261-288.

Savickas, M. L. (2005). The theory and practice of career construction. In S. D. Brown \& R. W. Lent (Eds.), Career development and counseling: Putting theory and research to work (pp. 42-70). Hoboken, NJ: John Wiley \& Sons.

Savickas, M. L., Nota, L., Rossier, J., Dauwalder, J. P., Duarte, M. E., Guichard, J., Salvatore, S., Van Esbroeck, R., \& Van Vianen, A. E. (2009). Life designing: A paradigm for career construction in the 21 st century. Journal of Vocational Behavior, 75(3), 239-250.

Schuman, H. (2008). Method and meaning in polls and surveys. Cambridge: Harvard University Press.

Sevier, R. A. (1993). Recruiting African-American undergraduates: A national survey of the factors that affect institutional choice. College and University, 68(1), 48-52.

Sperber, M. (2000). Beer and circus: How big-time college sports is crippling undergraduate education. New York: Henry Holt \& Company, Inc.

Stier, W. F. (1993). Alternative career paths in physical education: Sport management. Washington, DC: ERIC Clearinghouse Digest.

Ulrich, D., \& Parkhouse, B. (1982). An alumni orientated approach to sport management curriculum design using performance ratings and a regression model. Research Quarterly for Exercise and Sport, 53(1), 64-72.

Weese, W. J. (2002). Opportunities and headaches: Dichotomous perspectives on the current and future hiring realities in the sport management academy. Journal of Sport Management, 16(1), 1-17.

Weight, E. A., \& Zullo, R. H. (2015). Administration of intercollegiate athletics. Champaign, IL: Human Kinetics.

Whang, H. W., \& Bernhard, L. M. (2014, April). Intersecting identities and college choice processes: Race related differences in college enrollment among first-generation students. Paper presented at the Annual Meeting of the American Educational Research Association. Philadelphia, PA. 
Won, D., Bravo, G., \& Lee, C. (2013). Careers in collegiate athletic administration: Hiring criteria and skills needed for success. Managing Leisure, 18(1), 71-91.

\section{Biographies}
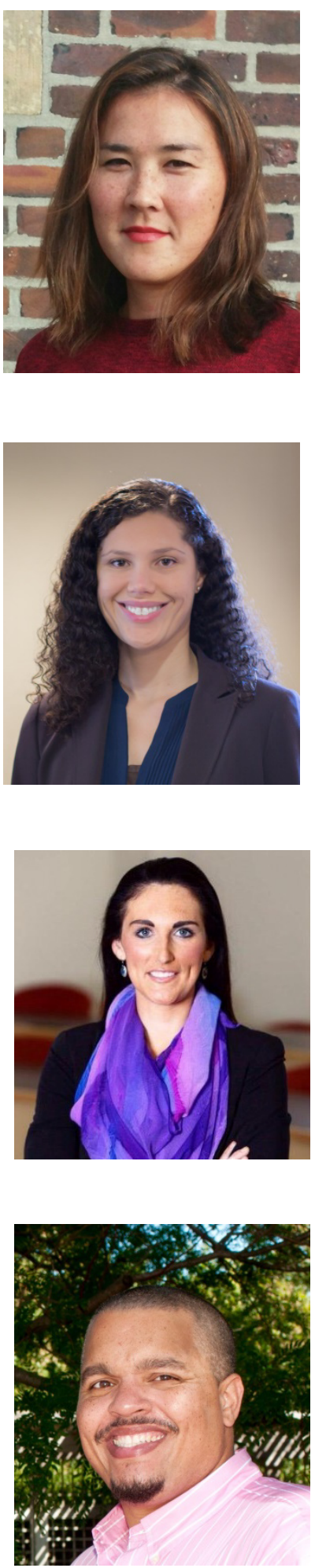

Dr Kristina Navarro serves in a joint role as an Assistant Professor in the College of Education and Professional Studies at the University of Wisconsin-Whitewater and the Director of Student-Athlete Engagement. In this role she oversees the higher education leadership and higher education athletic administration graduate programs.

Derek A. Houston, $\mathrm{PhD}$, holds research appointments with the Illinois Science, Technology, Engineering, and Mathematics (I-STEM) Education Initiative and the Center for Culturally Responsive Evaluation and Assessment (CREA), both at the University of Illinois at UrbanaChampaign. Additionally, he is currently an Adjunct Assistant Professor of Adult and Higher Education at the University of Oklahoma. His research interests include access issues across the P-20 educational pipeline, equity issues relative to intercollegiate athletics and studentathletes, specifically NCAA Division I, and program evaluation. 